\title{
Reflecting on the Political Zeitgeist. Post-truth Politics, Declining Parliaments, and Embodied Concerted Action
}

\author{
Katja Kahlina, University of Helsinki
}

With this last issue of 2018, Redescriptions have come to a turning point marked by the change in the position of editor-in-chief. Tuija Pulkkinen is undertaking the position of the first editor-in-chief, while Kari Palonen will continue to act as the second editor-in-chief. Reflecting this change, this last issue with Manchester University Press brings the articles by both Tuija Pulkkinen and Kari Palonen, together with two other articles. In addition to showcasing the unique focus of Redescriptions on the conceptual moves within political theory, conceptual history and feminist thought, all the articles included in this issue reflect upon some of the most salient issues of present political moment, tapping in this way into the key debates in the fields of political and feminist theory. Whether discussing the notion of alternative facts and post-truth politics (Palonen), the value of parliamentary debates in the time of their declining power (Rozenberg), or reflecting upon the notion of embodied concerted action (Pulkkinen and Castelli), the articles in this issue have one thread in common: they all see politics in the wider sense of agonistic conflicts and clashes of perspectives which are not only bound to political institutions in the strict sense, but which also take place in the spheres that are not immediately seen as political, such as scholarly debates or public squares. Based on such approach, each article in this volume in its own way re-affirms the value of debates, confrontations, and plurality of perspectives in the political moment marked by the rise of authoritarian governments and declining power of public debates.

In his article, Kari Palonen draws on Max Weber's writings on social sciences and reality, truth and objectivity to discuss one of the most debated concepts in contemporary politics - that of post-truth politics and the related 
notion of alternative facts. In this regard, Palonen brings to surface the points in Weber's work where Weber argues for the plurality of perspectives and the value of the ongoing debates and different interpretations of particular social phenomena. While drawing on Weber's rejection of the idea that there can be a single definite truth about social reality and his emphasis on the importance to keep the quest for truth open through ongoing debates and confrontations of different interpretations, Palonen critically reflects upon the current trend of countering the "post-truth" politics by invoking the "cult of facts." Instead, Palonen argues for the view that facts are neither true nor false per se but are always matter of different interpretation. The competing interpretations of facts, argues Palonen, represent the key element of political and scholarly debates. This point reveals the current fuss around alternative facts as trivial and misplaced. Instead, Palonen proposes that potentially problematic claims, such as those made by Trump or in the context of Brexit debates, be rejected not in the name of some irrefutable facts of truth, but on the grounds of their harmful implications and potential negative ramifications.

The important value that public debates have in the social and political life has also been affirmed by Olivier Rozenberg in his article on the role of parliamentary debates in the context of their declining relevance in contemporary political moment. Although the party control of parliamentary votes has strengthened, which made the voting results more predictable, Rozenberg argues that parliamentary debates still fulfil some important social and political functions. He regards parliaments as playing an important role in institutionalising the conflict over different values and interpretations and channelling it into structured political debates. These debates, although perhaps ceasing to have significant influence on the voting results, still make visible the positions taken by the MPs, thus positively contributing to the accountability of political actors. At the same time, parliamentary debates also open up the space for more elaborate justifications and clarifications of the policies under question and bring closer to surface the ideology underpinning the particular decisions.

Federica Castelli in her article moves away from the institutionalised political practices towards rethinking the politics as embodied practice. Drawing on feminist scholars Adriana Cavarero, Nicole Loraux and Judith Butler who all in different ways claim the centrality of body and embodied subjectivity in politics, Castelli argues for the concept of politics as embodies concerted action. Such concept stands in opposition to a modern notion of politics based on the idea of universal disembodied subject by placing emphasis on the relationalities and interdependencies of embodied subjects in public spaces such as streets and squares. Such conception of politics as embodied practice of performing in public space, Castelli argues, represents an important perspective for rethinking the idea of democracy. 
Finally, Butler's ideas of embodied subjectivity and concerted action have also, albeit in very different way, been the tackled in Tuija Pulkkinen's article. In her contribution to this issue, Pulkkinen discusses the ways in which Butler's concept of "human" in Butler's recent book Notes Toward a Performative Theory of Assembly departs from the phenomenological-existential tradition. Pulkkinen's discussion is based on the analysis of two key concepts employed in Butler's theory of embodied public action - that of "appearing" and "plurality" - which also play a prominent role in the phenomenological-existentialist tradition of Hannah Arendt and Adriana Cavarero. While reading Butler's understanding of "appearing" and "plurality" against Arendtian uses, Pulkkinen finds a systematic move in Butler's employment of these concepts. This move consists of stripping these concepts of their strong philosophical charge, thereby changing their meaning. Pulkkinen calls this move discharging. She sees this strategy of discharging in Butler's work as an example of philosophico-political move, a manoeuvre in the politics of philosophy, which allows Butler to resignify the phenomenological-existentialist idea of abstracted "human".

Although this is the last issue of Redescriptions that is published by Manchester University Press, it is by no means the last Redescriptions issue. Starting from the next issue, Redescriptions will be published by another publisher, with some slight changes in the journal appearance and accessibility. More about this in the next issue. Stay tuned! 